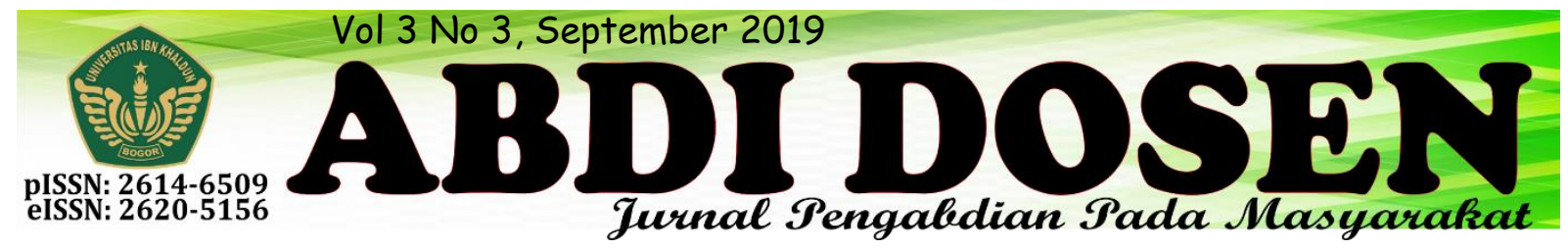

\title{
PEMBERDAYAAN MASYARAKAT MELALUI PENINGKATAN MUTU PENDIDIKAN, KEAGAMAAN, EKONOMI DAN KESEHATAN DI DESA CIARUTEUN UDIK
}

\author{
Indira Chotimah ${ }^{1}$, Imanda Rizkatria Utami ${ }^{2}$ \\ indira@uika-bogor.ac.id ${ }^{1}$ \\ imandautami@gmail.com ${ }^{2}$ \\ Fakultas Kesehatan Universitas Ibn Khaldun ${ }^{1}$, Mahasiswa KKN Kelompok 23 Tahun $2018^{2}$
}

\begin{abstract}
ABSTRAK
Pendidikan adalah proses mengembangkan kemampuan diri sendiri dan kekuatan individu. Yang mana setiap warga negara berhak untuk mendapatkannya baik secara formal, non formal maupun pendidikan agama yang dampaknya dapat dirasakan oleh lapisan masyarakat, pendidikan penting didapat karena dapat membangun karakter individu serta dapat membantu untuk kemajuan bangsa. Selain masalah pendidikan, keperdulian terhadap perilaku hidup bersih dan sehat juga penting untuk diperhatikan karena minimnya kesadaran akan kepentingan perilaku hidup bersih dan sehat. Terkait dengan kesehatan masalah lingkungan pun perlu diperhatikan karena keperdulian terhadap lingkungan sekitar pun masih minim di masyarakat, seperti membuang sampah sembarangan, membiarkan air menggenang dan lain sebagainya. Ini akan berdampak pada masalah kesehatan warga sekitar dan menyebabkan penyakit mudah timbul. Mengajarkan anak untuk menabungharus di tanamkan sejak dini agar bisa menjadi orang yang gemar menabung dan mempunyai masa depan yang cerah karena sudah terbiasa menyisihkan sebagian uang untuk kepentingan masa depannya.
\end{abstract}

Kata Kunci : Pendidikan, Kesehatan, Lingkungan, Ekonomi

\section{PENDAHULUAN}

Kuliah Kerja Nyata (KKN) merupakan salah satu bentuk pengabdian kepada masyarakat yang dilakukan oleh mahasiswa secara interdisipliner, institusional, dan kemitraan sebagai salah satu wujud dari tridharma perguruan tinggi.KKN tematik adalah program $\mathrm{KKN}$ dengan fokus yang spesifik dengan ciri-ciri relevan dengan program pembangunan daerah atau pemerintah pusat, dan relevan dengan kebutuhan masyarakat.

Desa Ciaruteun Udik adalah salah satu desa yang dilintasi oleh Sungai Ciaruteun yang bersumber dari mata air
Gunung Salak Bogor. Seiring berkembangnya waktu, masyarakat menamai wilayah ini dengan Ciaruteun, karena aliran sungai ini berada di hulu sungai maka bernama Ciaruteun Udik.

\section{Kondisi Geografis}

Secara geografis, Desa Ciaruteun Udik terletak di Kecamatan Cibungbulang, Kabupaten Bogor, Jawa Barat, Indonesia. Luas wilayah desa ini yaitu 205.110 hektar. 
Batas Wilayah

\begin{tabular}{|c|l|l|}
\hline No & \multicolumn{1}{|c|}{$\begin{array}{c}\text { Arah Mata } \\
\text { Angin }\end{array}$} & \multicolumn{1}{|c|}{ Perbatasan } \\
\hline 1 & Utara & $\begin{array}{l}\text { Desa Cibuntu } \\
\text { Kec. Ciampea }\end{array}$ \\
\hline 2 & Selatan & $\begin{array}{l}\text { Desa Cibening } \\
\text { Kec. Pamijahan }\end{array}$ \\
\hline 3 & Barat & $\begin{array}{l}\text { Desa Cimayang } \\
\text { Kec. Pamijahan }\end{array}$ \\
\hline 4 & Timur & $\begin{array}{l}\text { Desa Ciampea } \\
\text { Udik Kec. } \\
\text { Ciampea }\end{array}$ \\
\hline
\end{tabular}

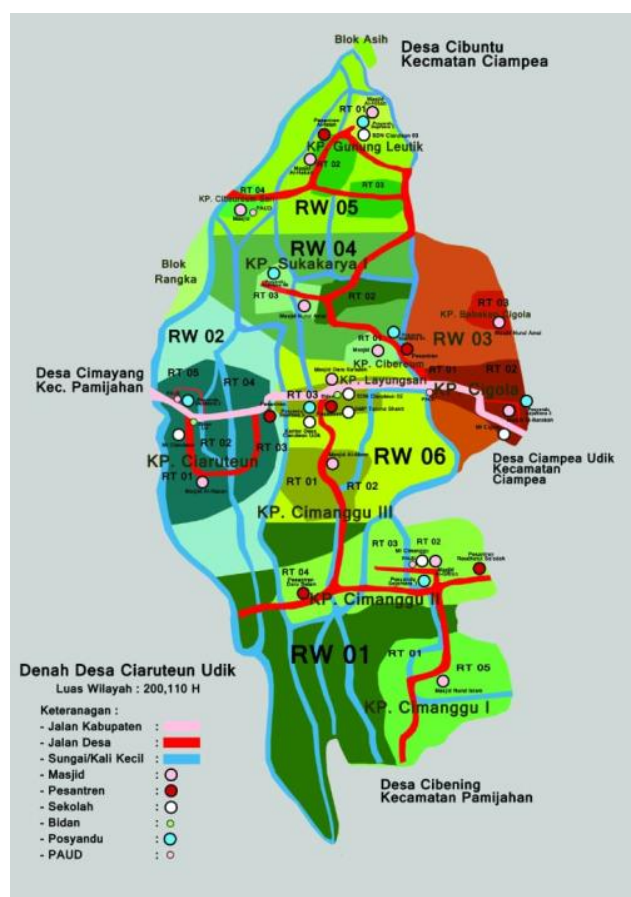

Secara umum, kondisi masyarakat Desa Ciaruteun Udik, Kp. Layung Sari RT 03 RW 06 cukup maju, cenderung mudah bersosialisasi, dan menerima pendatang baru dengan tangan terbuka. Para mahasiswa yang akan melakukan KKN Terintegrasi disambut dengan antisipasi baik dari masyarakat. Mereka menaruh ekspektasi yang cukup tinggi pada mahasiswa/i Kelompok 23 KKN UIKA 2018 karena ini adalah kedua kalinya mereka menerima mahasiswa KKN di Desa Ciaruteun Udik. Hal tersebut didukung dengan partisipasi masyarakat dan apresiasi dari pihak-pihak yang berwenang selama kami melaksanakan program kerja.

Dapat kami simpulkan bahwa kondisi masyarakat Kp. Layung Sari RT 03 RW 06 Desa Ciaruteun Udik terlihat baik, bersahabat dan menerima orangorang pendatang baru dengan tangan yang terbuka tanpa adanya konflik dari berbagai pihak. Perumusan rencana starategis dalam pengembangan Desa Ciaruteun Udik yang akan kami lakukan adalah dengan menggunakan analisis SWOT (Strengths, Weaknesses, Opportunities, dan Threats) terhadap desa. Oleh karena itu kami mencoba menganalisis hal-hal tersebut yakni:

\section{Strengths (Kekuatan)}

Berdasarkan pengamatan dan inventarisasi kondisi dan potensi Desa Ciaruteun Udik, dapat diidentifikasikan beberapa faktor yang menjadi kekuatan internal desa ini, antara lain:

a. Lahan pertanian berupa sawah dengan luas $\pm 176,110$ hektar dan lahan untuk perkebunan singkong dan sayur seluas \pm 29 hektar sehingga berpotensi untuk meningkatkan perekonomian masyarakat setempat.

b. Kesadaran masyarakat akan pendidikan agama, tampak dari antusiasme anak-anak dan pemuda/i saat mengikuti kegiatan keagamaan.

c. Lingkungan masyarakat yang cukup aman dan kondusif dapat mendukung proses pembangunan masyarakat yang terarah.

\section{Weaknesses (Kelemahan)}

Selain memiliki berbagai kelebihan, setiap desa pasti memiliki kelemahan. Dari hasil identifikasi diperoleh kelemahan Desa Ciaruteun Udik antara lain:

a. Tidak adanya tempat pembuangan sampah sementara, sehingga sampah- 
sampah harus dibakar dan menyebabkan polusi. Hal ini dikarenakan masyarakat kampung selain Layung Sari merasa keberatan jika harus diadakan penarikan biaya pengangkutan sampah tiap minggunya.

b. Minimnya sarana penunjuk arah dan rambu lalu lintas juga menjadi kelemahan desa ini sehingga sebagian masyarakat yang belum kenal Desa Ciaruteun Udik akan kebingungan mencari lokasi desa dan terdapat titik rawan kecelakaan di jalan menuju desa.

c. Program kegiatan yang ada di desa saat ini masih belum memiliki tolak ukur yang memadai, namun dalam pelaksanaannyapemerintahan desa sudah berjalan dengan cukup baik.

\section{Opportunities (Peluang)}

Selain mengidentifikasi faktor internal berupa kelemahan dan kelebihan, pihak desa juga harus mampu menangkap peluang yang datang dari lingkungan eksternal. Hal-hal yang dapat diidentifikasi antara lain:

a. Adanya kebijakan pembangunan desa dari pemerintah kabupaten yang mana desa diberikan dana yang besar untuk membangun dan merawat fasilitas umum desa, seperti pelebaran jalan, penambahan ruangan di gedung SDN
Ciaruteun Udik 02 agar kegiatan belajar lebih optimal.

b. Antusiasme masyarakat, terutama anak-anak sekolah dan pemuda/i terhadap program-program kerja mahasiswa KKN sehingga memungkinkan terjadinya perubahan pola pikir ke arah yang lebih baik; kesadaran akan bahaya bullying, kemauan untuk mengikuti kajian agama, dan mampu memanfaatkan teknologi secara efisien.

\section{Threats (Ancaman)}

Berikut adalah hasil identifikasi hal-hal yang dapat menjadi ancaman bagi Desa Ciaruteun Udik:

a. Terindikasinya gizi buruk pada beberapa balita dibeberapa dusun disebabkan rendahnya kunjungan orang tua ke kegiatan Posyandu dan rendahnya daya beli keluarga tersebut. Sehingga apabila kondisi tersebut tidak segera diurus secara serius akan berdampak semakin parah pada kesehatan balita.

b. Perkebunan dan empang dapat menjadi sarang nyamuk dan memungkinkan terjadinya wabah demam berdarah.

c. Kebiasaan membakar sampah di pekarangan rumah atau pinggir jalan menimbulkan polusi yang dapat meningkatkan risiko gangguan pernapasan. 


\section{METODE PENGABDIAN}

\section{Tahap Pelaksanaan}

Tahap pelaksanaan kegiatan KKN sebagaimana tampak pada bagan berikut:

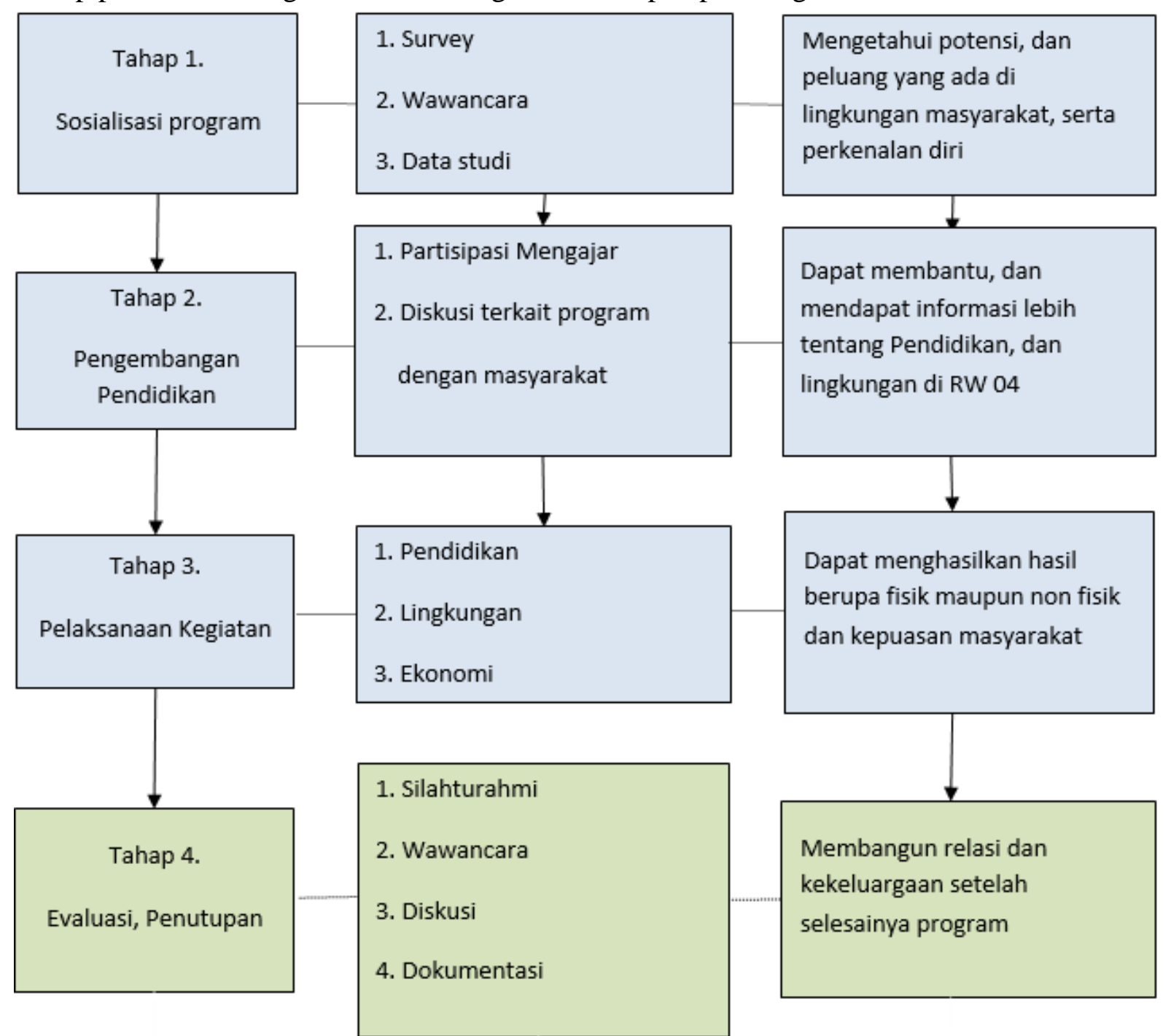

\section{Metode Pendekatan}

Pendekatan yang digunakan dalam kegiatan KKN Terintegrasi ini adalah:

a. Pendekatan Religius, di mana mahasiswa/i KKN terlibat aktif dalam kegiatan keagamaan Masjid dan Majelis Darussa'adah.

b. Pendekatan Organisasi, di mana mahasiswa/i Kelompok 23 dan Paguyuban Pemuda/i Layung Sari saling bekerjasama dalam pelaksanaan program-program besar seperti Perlombaan 17 Agustus, Qurban, dan Pemeliharaan Masjid dan Majelis Darussa'adah. c. Pendekatan Kekerabatan, artinya bahwa pembinaan yang dilakukan senantiasa dikaitkan dalam rangka meningkatkan kesadaran akan pentingnya kesehatan, pendidikan, dan kreatifitas.

d. Pendekatan berdasarkanKarakter Masyarakat, yakni pembinaan yang dilakukan akan disesuaikan dengan karakter masyarakat setempat, sehingga masyarakat dapat berpartisipasi langsung terhadap kegiatan-kegiatan yang dilaksanakan. 


\section{Partisipasi Masyarakatdalam}

\section{Pelaksanaan Program}

a. Masyarakat hadir dalam programprogram besar yang dilaksanakan oleh mahasiswa/i Kelompok 23 KKN UIKA 2018.

b. Masyarakat memberikan bantuan dana ketika dilakukannya kegiatan pemeliharaan Masjid dan Majelis Darussa'adah.

c. Masyarakat mempersilakan untuk memakai fasilitas desa yang ada dan memberikan kesempatan kepada mahasiswa/i KKN untuk tampil menyampaikan beberapa program.

\section{REALISASI PROGRAM}

Program-program kerja Kelompok 23 KKN UIKA 2018 yang sudah terealisasi adalah sebagai berikut:

\section{Bidang Pendidikan}

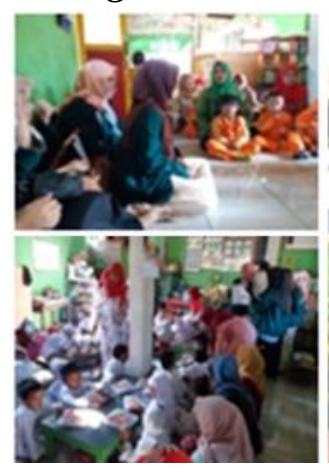

Pengajaran

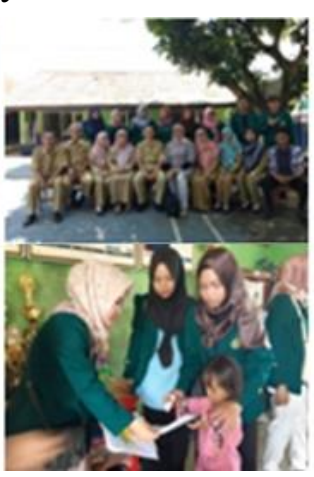

dengan media

sederhana dan media interaktifdi SDN Ciaruteun Udik 02 untuk menggali potensi peserta didik pada saat pembelajaran berlangsung dengan memberdayakan kemampuan yang dimiliki oleh mahasiswa/i, serta mendidik secara langsung peserta didik untuk mengetahui sejauh manakah kemampuan yang dimiliki oleh setiap peserta didik. Dapat diketahui bahwa siswa/i sangat jenuh ketika proses pembelajaran, maka disinilah peran sebagai mahasiswa/i untuk merubah kondisi tersebut agar proses pembelajaran

\section{Langkah Evaluasi}

Evaluasi yang dilakukan adalah sebagai berikut:

a. Evaluasi proses yang terkait dengan perencanaan, pelaksanaan, dan pantauan kegiatan. Evaluasi dilaksanakan oleh Kelompok 23 sebelum pelaksanaan program.

b. Evaluasi hasil yang dilaksanakan setiap malam setelah kegiatan dilaksanakan. Evaluasi ini membahas kekurangan yang terjadi selama kegiatan berlangsung dan solusi agar hal tersebut tidak terulang di program kerja selanjutnya.

menjadi lebih aktif dan menyenangkan, serta tujuan yang diharapkan pun dapat tercapai.

\section{Bidang Keagamaan}

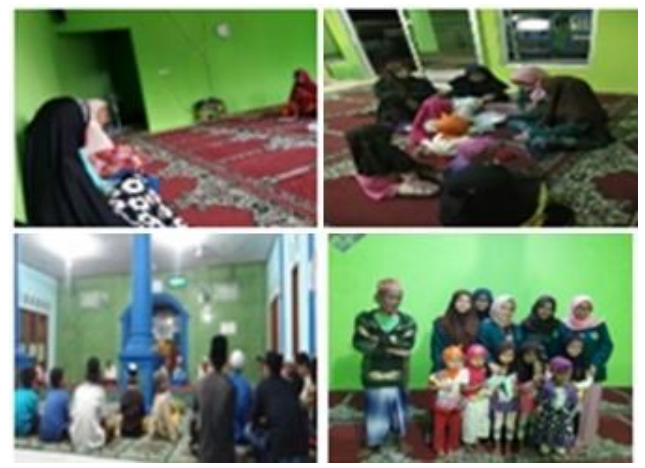

Secara umum di Kampung Layung Sari terdapat pengajian rutin mingguan yang diikuti oleh ibu-ibu dan bapak-bapak, selain di Kampung Layung Sari ada kegiatan pengajian rutin khususnya bapakbapak di kampung lain yaitu Kampung Cimanggu dan Kampung Cigola, serta pengajian rutin setiap hari yang diikuti oleh anak-anak usia 3-7 dilaksanakan setiap setelah sholat maghrib sampai menjelang isya kecuali pada malam Senin.Pengajian rutin mingguan yang diikuti oleh ibu-ibu yaitu pada hari Kamis sore, dengan tema menjelaskan Idul Adha 
serta pentingnya berpuasa sebelum Idul Adha.Pengajian rutin anak-anak dilaksanakan setiap hari dengan pokok pembahasan yang berbeda,adapun pembahasannya mengenai BTQ (Baca, Tulis,Qur'an), Tajwid, Do'a sehari-hari \& Fiqh.

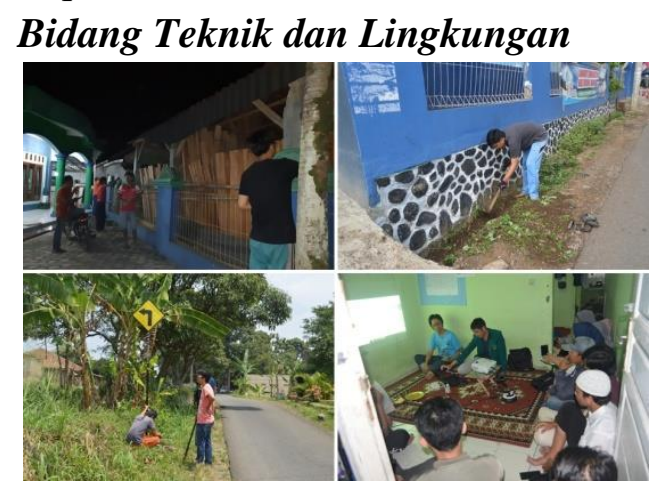

a. Pengecatan Masjid

Pengecatan masjid dilaksanakan di Masjid Darussa'adah yang terletak di Kampung Layung Sari RT 03/ RW 06 Desa Ciaruteun Udik. Antusiasme masyarakat yang tinggi baik dalam segi tenaga maupun material sangat membantu dalam pelaksanaan program kerja ini.

b. Pembersihan Saluran Drainase

Pengalihfungsian saluran drainase menjadi tempat pembakaran sampah serta pembiaran tumbuhnya tanaman di area saluran air akan berdampak buruk, baik dalam jangka pendek maupun panjang. Bersama masyarakat sekitar, program kerja pembersihan saluran drainase bertujuan mengembalikan fungsi awal saluran drainase sebagai tempat mengalirnya air.

c. Pemasangan Rambu Lalu Lintas (Penunjuk Arah)

Jalan yang berada di desa Ciaruteun Udik ini merupakan jalan utama penghubung antara desa Ciaruteun Udik dan Desa Ciampea Udik serta menghubungkan pula antara Kecamatan Pamijahan, Kecamatan Cibungbulang, dan Kecamatan Ciampea yang merupakan jalan padat oleh aktivitas sekolah, umum, serta jalur rekreasi yang berada di daerah tersebut.Pemasangan rambu lalu lintas sangat diperlukan karena terdapat beberapa titik rawan kecelakaan karena kurangnya petunjuk arah.

d. Pelatihan Melek Teknologi

Tujuan dilakukannya kegiatan ini adalah memberi pengetahuan tambahan mengenai teknologi informasi yang nanti akan bermanfaat bagi masyarakat Desa Ciaruten Udik, khususnya pemuda/i yang berada dalam usia produktif.

\section{Bidang Ekonomi}

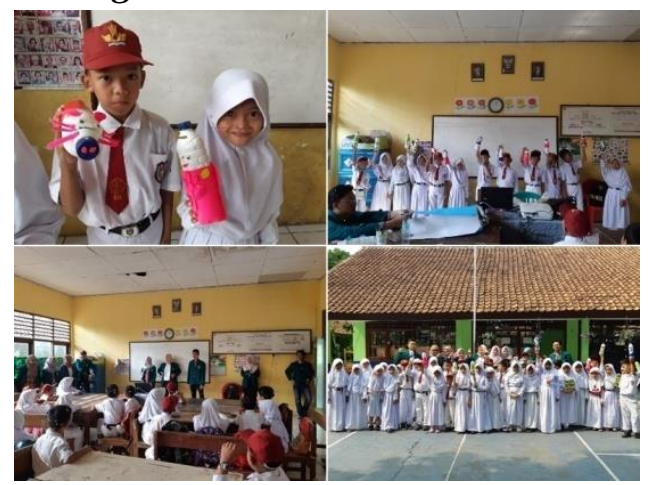

Penyuluhan pentingnya menabung sejak dini dan pembuatan celengan dari botol air mineral bekas di SDN Ciaruteun Udik 02. Mendidik anak dalam menabung bahwa menabung harus di tanamkan sejak dini agar bisa menjadi orang yang gemar menabung dan mempunyai masa depan yang cerah karena sudah terbiasa menyisihkan sebagian uang untuk kepentingan masa depannya. Perilaku hidup hemat dan sehat ini diharapkan bisa memotivasi anak-anak untuk terbiasa hidup sederhana dan bisa membantu orang lain. 


\section{Bidang Kesehatan}

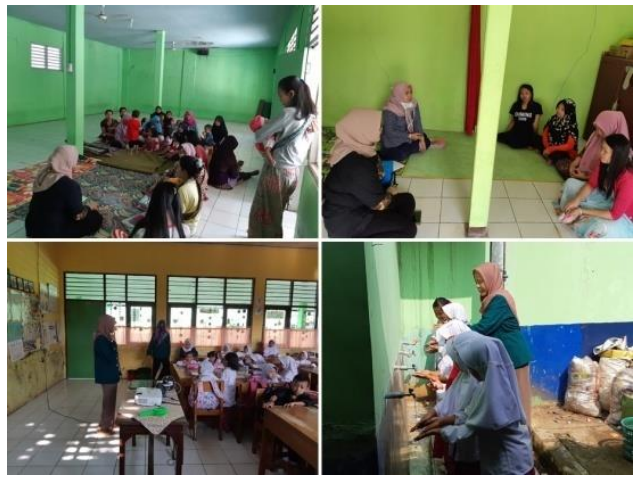

a. Penyuluhan Gizi Balita dan Ibu Hamil

Penyuluhan gizi balita di Posyandu

Tunas Sejahtera 2 dilakukan agar kebutuhan gizi yang diterima oleh balita terpenuhi untuk dapat memelihara keseimbangan tubuh dan baik untuk pertumbuhan balita. Penyuluhan ibu hamil tentang gizi yang baik dan seimbang untuk ibu dan janinnya, keadaan gizi dapat memengaruhi kesehatan ibu dan janin, pertumbuhan dan perkembangan janin, serta persiapan laktasi ibu, sehingga kebutuhan makanan ibu meningkat.

b. Penerapan Hidup Bersih dan Sehat(Sikat Gigi dan Cuci Tangan)

Penyuluhan tentang sikat gigi yang dilakukan di SDN Ciaruteun Udik 02 ini penting dilakukan untuk menanamkan pola hidup sehat sejak dini serta untuk menjaga

\section{KESIMPULAN}

Masyarakat Desa Ciaruteun Udik RT 03 RW 06 sangat antusias dengan program kerja Kelompok 23 KKN UIKA 2018. Masyarakat sangat membantu dalam melaksanakan segala pelaksanaan kegiatan sehingga dapat berjalan dengan lancar. Setelah melakukan kegiatan KKN Terintegrasi di Kampung Layung Sari Desa Ciaruteun Udik, masyarakat mendapakan dampak-dampak positif yang dihasilkan dari program-program yang terdiri dari beberapa bidang diantaranya: kebersihan gigi dan mulut. Sedangkan kebersihan tangan merupakan hal yang harus diperhatikan saat akan menyentuh makanan sehingga terhindar dari penyakitpenyakit tertentu.

\section{Bidang Hukum}

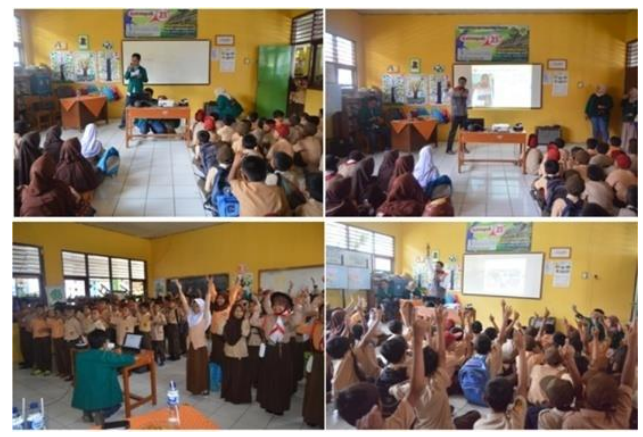

Perilaku bullying di lingkungan sekolah dapat menciptakan suasana lingkungan yang kurang mendukung terhadap perkembangan siswa, baik dalam bidang akademik maupun bidang sosial. Perilaku bullying dapat menyakiti siswa sehingga mereka merasa tidak diinginkan dan ditolak oleh lingkungannya. Hal ini tentunya akan membawa efek negatif pada performa siswa disekolah.Program sosialisasi ini menggunakan pendekatan dalam bentuk penyuluhan, serta sasarannya ke siswa/i SDN Ciaruteun Udik 02.

a. Metode pembelajaran baru dan variatif yang meningkatkan minat belajar siswa.

b. Keikutsertaan dalam kajian agama dan baca tulis Qur'an.

c. Kesadaran untuk hidup hemat dan menabung sejak dini.

d. Kesadaran untuk menjaga kebersihan diri melalui penerapan hidup bersih dan sehat.

e. Terciptanya lingkungan yang kondusif, bersih, dan nyaman. 
f. Pengenalan manfaat teknologi dalam kehidupan sehari-hari.

g. Kesadaran akan bahaya bullying.

\section{SARAN}

Berdasarkan kesimpulan yang telah dijabarkan, maka kami mengajukan rekomendasi yang sekiranya dapat bermanfaat dan dapat dipertimbangkan, antara lain:

a. Warga Desa Ciaruteun Udik Kecamatan Cibungbulang memiliki mata pencaharian sebagai petani yang menanam singkong, ubi, sayur-mayur, dan juga ayam potong. Maka dari itu

\section{REFERENSI}

Administrator. (2015). Pengertian Pendidikan, Tujuan \& Menurut Para Ahli. Diambil dari http://www.artikelsiana.com/2015/08 /pengertian-pendidikan-tujuanmanfaat.html?m=1 tanggal 13 September 2018.

Administrator. (2018). KKN Tematik 2018. Diambil dari: http://kkn.lppm.upi.edu/index.php/in fo/sekilas tanggal 13 September 2018.

Kader Posyandu Tunas Sejahtera 2 Desa Ciaruteun Udik Kec. Cibungbulang Kabupaten Bogor.

Kepala PAUD Tunas Sejahtera Kp. Cigola Desa Ciaruteun Udik Kec. Cibungbulang Kabupaten Bogor. sangat diharapkan bantuan dan pembinaan dari pihak terkait dalam rangka memajukan kesejahteraan masyarakat.

b. Warga Desa Ciaruten Udik Kecamatan Cibungbulang diharapkan untuk lebih memperhatikan masalah kebersihan lingkungan untuk terhindar dari penyakit seperti demam berdarah dan gangguan pernapasan.

Kepala SDN Ciaruteun Udik $02 \mathrm{Kp}$. Layung Sari RT 03 RW 06 Desa Ciaruteun Udik Kec. Cibungbulang Kabupaten Bogor.

Sarjono, A. DPRD Kota Bogor.

Sekdes Ciaruteun Udik. (2017). RKP Desa Ciaruteun UdikKecamatan CibungbulangKabupaten Bogor Tahun 2018.

Shabir, M, dkk. (2017). Pemberdayaan Masyarakat Melalui Peningkatan Mutu Pendidikan dan Kesehatan di Desa Bojong Sempu, Kecamatan Parung - Kabupaten Bogor. Jurnal Mahasiswa Volume 01, Nomor 01 Desember 2017. 